\title{
Relevance of Biogas in Rural Area: Women Perspectives
}

Khadka Gopal

\begin{abstract}
:
Biogas is a form of clean cooking mechanism. As a proven and widely-used global source of energy, it is popular all over the world. To explore the women's views about the importance of biogas in rural settings of urban areas, this study is conducted as the title of relevance of biogas in rural areas: women perspectives. It is based on the theoretical assumption of cultural feminism. It employs exploratory research design and is based on both primary and secondary sources of data. The study revealed that there is high relevance of biogas in rural farm based society in Nepal. Through women perspectives, health and sanitation; easy and sustainable operation; time and resource saver; cheap and low maintenance are its major importance. Biogas plant helps to reduce the untiring busy schedule of women in household activities. It suggests that concerned authorities should make effective institutional frameworks to empower women in their homeland by optimum utilization of leisure time made possible by the use of biogas.
\end{abstract}

Keywords: biogas, rural, gender equality, relevance, cultural feminism

\section{Introduction}

Biogas is a blend of gas, primarily methane and carbon dioxide, produced by bacteria acting on organic materials in an oxygen-free environment. The gas is a smoke-free combustible that burns with a blue flame, similar to that of liquid petroleum gas (Giordano et.al, 2018). Biogas is a viable source of energy in Nepal. It is a boon for farmers due to its multiple uses in their livelihood. By providing bio- slurry, a byproduct of biogas which has high-nitrogen, it helps to multiply the output of agricultural production and generate a large number of green jobs. On one hand, it reduces the deforestation rate and on the other hand; it increases the status of health and sanitation. It has no bias in terms of caste, class, gender, religion and ethnicity.

The average $4 \mathrm{~m}^{3}$ biogas systems requires dung from two cows or buffalos and an equal amount of water per day for its operation, and it provides enough biogas to cook for about 2.4 hours. Moreover, the biogas generated can be used for lighting, particularly the places where other fuels for lighting are unavailable, and the anaerobic digestion process produces bio-slurry, manure with a higher fertilizer value than dung, which can be used to fertilize crops, enhancing agricultural production (Giordano et.al ,2018). Biogas, a plant following an all-natural process called anaerobic digestion to turn waste into clean energy, is a sustainable energy source ideally used for cooking, lighting, heating and electricity generation with zero net greenhouse emissions. Biogas is an eco-friendly sustainable source of renewable energy. The common conclusion of various reports related to biogas stated that 
clean cook stoves and fuels have the potential to reduce deaths from Smoke-related illnesses, mitigate climate change and lower air pollution. They can provide new sources of livelihoods for women and reduce the risk and drudgery of fuel collection and lower household expenditures on cooking fuel.

Women, who have responsibility to manage domestic burden related to the kitchen, are the primary users of biogas in Nepal. The respondents confirmed that biogas is their true friend due to its help to save time, to reduce work-load, to maintain health, and to make a job convenient. The gender issue assigns tightly defined roles to men and women in family and society, which creates discriminatory attitudes and practices throughout the society, have a foundation in the family setting and reflected in the regular household activities. Low access to family property, lack of education, low economic status, lack of access to social issues, regular domestic burden hide their decision making power. In Nepalese family system, women have low status. Prior studies about biogas focus the view of the family head i.e. male, which hides the reality so it is essential to explore the real view of the true user of actual technology for assessing its effectiveness. This study provides the real reflection of targeted consumers for concerned authority.

Things have changed for the better, but not for all women and not in all domains of gender equality. Progress has been slow and limited for some women in very poor countries, for those who are poor, even amid greater wealth, and for those who face other forms of exclusion because of their caste, disability, location, ethnicity, or sexual orientation (World Bank 2011). Development of Technology and gender gap are inversely proportional with one another. Various researches prove that Modern technology helps to bridge the gender gap. This study is helpful for gender analysts to calculate the role of biogas technology for reducing gender gap in rural farmland.

Biogas is economically and environmentally compatible to use. Being the pioneer and most successful Public Private Partnership (PPP) model, it earns millions of dollars every year through the carbon trading system. So, without any doubt it can be helpful to put a landmark contribution by increasing awareness and fostering the positive attitude among the Nepalese society towards the development of biogas plants to promote a clean development mechanism in Nepal.

\section{Biogas support program and its Impact}

Netherlands Development Organization launched the Biogas Support Program (BSP) in 1992, a donor-supported program, with the goal of constructing and disseminating household-scale biogas plants in rural Nepal as a mainstream renewable energy source. It highlighted the main aspects of impact created by biogas system on the population's income and livelihood, education, health, gender equality and environment. The use of biogas plants can entail direct monetary savings - estimated at US\$218 per year per household - in areas 
where fuel wood or kerosene is purchased for cooking. Reduced firewood collection means reduced time spent on procurement and fewer loads carried by women and children. The time saved and the light generated by biogas lamps can be used for income generation activities. Productivity gains via the use of biogas slurry as fertilizer. Around 90 biogas companies are working under the program improve employment and business opportunities. The most visible benefit of adopting biogas is reduced indoor air pollution, observed by about $98 \%$ of users of biogas plants. Reduced indoor pollution contributes to reduced child mortality rates. Biogas lamps provide brighter light than kerosene lamps, which helps children study during night hours. The introduction of toilet-linked biogas plants is often a starting point for communities to start using toilets, which reduces water contamination and related diseases, like cholera and eye and respiratory illnesses. The introduction of toilet linked biogas plants increased the percentage of households using toilets from $49 \%$ to about $76 \%$. . On average, a biogas plant can replace 2.5 to 3 tons of firewood and 6.5 liters of kerosene per year, equivalent to a reduction of around 3 tons of CO2 of GHG emissions. Reduce deforestation and forest degradation, through reduced use of firewood. Increased use of organic fertilizers reduced the use of chemical fertilizers. (Giordano et al, 2018).

\section{Role of women}

The role of women in developing countries has been recognized as the single most important factor when it comes to bringing about and sustaining long term social change. Women are farmers and foodproviders (contributing to agricultural output, general environmental maintenance and food security); they are business people and traders ( $40 \%$ of the world's labor force are women, not including informal work in the home, on the land, in the market place etc); they are heads of households (most of whom are likely to also have a full time job, as well as caring for children, elderly or sick relatives); they are mothers, careers and support workers (more often than not, in developing countries, this is voluntary); and they are community leaders, activists and rolemodels (stemming from their roles in society as mothers, careers and support workers). Development affects men and women differently, often with a more negative impact on women. This can undermine women's role, status and position within society and therefore perpetuates their inequality (Regan, 2012).

Women and men play different defined roles in energy production, distribution and utilization in households, communities and the market. Climate stresses on biomass resources are increasing the burden on many women, forcing them to travel even longer distances and spend more time fetching fuel wood, water and fodder. Improved modern energy services can improve women's socioeconomic status by reducing the time and effort involved in household chores and alleviating the health risk associated with current energy practices. There are several small scale clean technologies that can improve safety, 
employment and entrepreneurial opportunities for women. Technologies reduce women's challenges and increase their independence. Majority of the Nepalese populations still use traditional fuels such as fire wood, agricultural residues and dung cake etc inside their homes, which creates various socio-economic, environmental and health related adverse impacts on human health especially women. Biogas has played a vital role in improving the health status and thus uplifting the living standard of rural people by providing clean fuel.

\section{Theoretical Base:}

This study is based on the key assumptions of cultural feminism to analyze the relevance of biogas in rural areas. It shows that there is 'female nature' of 'female essence'. It assumes that due to the cultural attributes, there are different perspectives between male and female towards the same phenomena, event or object. So the perspective of men and women are varying about the relevancy of biogas.

The term "cultural feminism" dates back at least to the use of it in 1975 by Brooke Williams of Redstockings, who used it to denounce it and distinguish it from its roots in radical feminism. Other feminists denounced cultural feminism as betraying feminist central ideas. Alice Echols describes this as the "depoliticization" of radical feminism. The work of Mary Daly, especially her Gyn/Ecology (1979), has been identified as a movement from radical feminism into cultural feminism (Lewis, 2019).

Cultural feminism is a variety of feminism which emphasizes essential differences between men and women, based on biological differences in reproductive capacity. Cultural feminism attributes to those differences distinctive and superior virtues in women. What women share, in this perspective, provides a basis for "sisterhood," or unity, solidarity and shared identity? Thus, cultural feminism also encourages building shared women's culture. The phrase "essential differences" refers to the belief that gender differences are part of the essence of females or males, that the differences are not chosen but are part of the nature of woman or man. Cultural feminists differ as to whether these differences are based on biology or enculturation. Those who believe differences are not genetic or biological, but are cultural; conclude that women's "essential" qualities are so ingrained by culture that they are persistent (Lewis, 2019).

\section{Objectives}

This study has only one objective i.e. to explore the relevance of biogas in rural area through women perspective.

\section{Methods and Materials}

This study employs the exploratory research design to explore the relevance of biogas in rural settings of urban areas through women perspective. It is based on the idea of cultural feminism. Urlabari municipality ward no 9, Morang district is a study area where 125 households have domestic biogas plants. 60 women using both biogas and bio slurry in their 
Patan Pragya (Volume: 6, Number: 1 2020)

house since two years were selected as respondents through purposive sampling procedure for detailed study of biogas technology in its natural real-life context. It is based on both primary and secondary data. The primary data were collected through in-depth face-to-face structured interviews and observations .The secondary data were collected by reviewing biogas-related literature through search engines. After Pretesting the question of in-depth structured interview, Data were collected with minute observation by the active initiation of the researcher himself. The collected data has been checked, coded, categorized, organized and converted into a master data sheet. Data was presented in Table and figure by using msword and ms-excel. Data is analyzed descriptively through percentage, frequencies and average mean value.

\section{Result and Dicussion}

\section{Nature of respondents}

Table-1: Characteristics of sample respondents

\begin{tabular}{|l|l|l|}
\hline Variables & Number of respondents & Percentage \\
\hline 1.Ethnicity & & \\
\hline Brahmin & 15 & $25 \%$ \\
\hline Chhetri & 20 & $33.3 \%$ \\
\hline Janajati & 25 & $41.7 \%$ \\
\hline Total & $\mathbf{6 0}$ & $\mathbf{1 0 0 \%}$ \\
\hline 2.Age groups(in years) & & \\
\hline $20-30$ & 12 & $20 \%$ \\
\hline $30-40$ & 25 & $41.7 \%$ \\
\hline $40-50$ & 23 & $38.3 \%$ \\
\hline Total & $\mathbf{6 0}$ & $\mathbf{1 0 0} \%$ \\
\hline 3. occupation & & \\
\hline Farming & 55 & $91.7 \%$ \\
\hline Service & 5 & $8.3 \%$ \\
\hline Total & $\mathbf{6 0}$ & $\mathbf{1 0 0} \%$ \\
\hline 4. Education & & \\
\hline Illiterate & 10 & $16.7 \%$ \\
\hline Literate & 50 & $83.3 \%$ \\
\hline Total & $\mathbf{6 0}$ & $\mathbf{1 0 0 \%}$ \\
\hline 5. level of education & & \\
\hline Primary & 30 & $60 \%$ \\
\hline Secondary & 15 & $30 \%$ \\
\hline Higher secondary & 5 & $10 \%$ \\
\hline Total & $\mathbf{5 0}$ & $\mathbf{1 0 0 \%}$ \\
\hline & &
\end{tabular}


Patan Pragya (Volume: 6, Number: 1 2020)

\begin{tabular}{|l|l|l|}
\hline 6. Religion & & \\
\hline Hindu & 35 & $58.3 \%$ \\
\hline Buddhist & 10 & $16.7 \%$ \\
\hline Kirat & 15 & $25 \%$ \\
\hline Total & $\mathbf{6 0}$ & $\mathbf{1 0 0} \%$ \\
\hline 7.family size(person) & & \\
\hline $1-4$ & 25 & $41.7 \%$ \\
\hline $5-8$ & 35 & $58.3 \%$ \\
\hline Total & $\mathbf{6 0}$ & $\mathbf{1 0 0} \%$ \\
\hline 8. Number of children (person) & & \\
\hline $1-2$ & 25 & $41.7 \%$ \\
\hline $3-4$ & 35 & $58.3 \%$ \\
\hline Total & $\mathbf{6 0}$ & $\mathbf{1 0 0} \%$ \\
\hline 9. size of biogas plant & & \\
\hline 4 cubic meter & 55 & $91.7 \%$ \\
\hline 6 cubic meter & 5 & $8.3 \%$ \\
\hline Total & $\mathbf{6 0}$ & $\mathbf{1 0 0} \%$ \\
\hline
\end{tabular}

Source:Field Survey, 2020

On the basis of table-1, respondents have heterogeneous nature in terms of age, ethnicity, religion and occupation. No one ethnic group is in majority. Janjati group includes tamang, rai and limbu. They belong to 20-50 yrs age groups. Most of them follow farming as their occupation and Hinduism as their religion. Most of them (83.3\%) are literate. Majority (60\%) of literate respondents have completed primary level education. They (91.7\%) have a small size (4 cubic meters) biogas plant. They have up to 8 members in the family and up to 4 numbers of children. All of them resided in small size family.5 respondents engaged as employed in primary level boarding school and cooperative institutions.

\section{Relevance of biogas in terms of health and sanitation}

Table-2 reveals the relevance of biogas in terms of health and sanitation. All respondents agreed that the incidence of mosquito, flies and insects are increased adversely due to open access of slurry pits and it is difficult to transport liquid manure to the field. Majority of them agreed that slurry helps to increase the production and productivity of farm land; convenience to manage kitchen gardens and production of organic food stuff .Majority of respondents agreed that due to the absence of a smoky environment, the interior of the kitchen is clean; easy and fast to wash the utensils; long life of utensils and reduction of hand skin problems.These all are related to smoke and dust of firewood and other fuel for cooking. 
Patan Pragya (Volume: 6, Number: 1 2020)

Table-2: Relevance of biogas in terms of health and sanitation

\begin{tabular}{|c|c|c|c|c|c|c|c|}
\hline $\mathrm{SN}$ & Variables & $(1)$ & $(2)$ & (3) & (4) & (5) & Total \\
\hline 1 & Clean and hygienic surrounding of home & $23.3 \%$ & $66.7 \%$ & $8.3 \%$ & $1.7 \%$ & -- & $100 \%$ \\
\hline 2 & Clean and hygienic interior of kitchen & $16.7 \%$ & $68.3 \%$ & $11.7 \%$ & $1.7 \%$ & $1.7 \%$ & $100 \%$ \\
\hline 3 & Easy to manage kitchen garden & $8.3 \%$ & $75 \%$ & $11.7 \%$ & $1.7 \%$ & $3.3 \%$ & $100 \%$ \\
\hline 4 & Reduction of waterborne diseases & $16.7 \%$ & $73.3 \%$ & $8.3 \%$ & $1.7 \%$ & - & $100 \%$ \\
\hline 5 & Reduction of respiratory diseases & $11.7 \%$ & $78.3 \%$ & $8.3 \%$ & $1.7 \%$ & - & $100 \%$ \\
\hline 6 & Reduction of skin problems & $16.7 \%$ & $73.3 \%$ & $5 \%$ & $3.3 \%$ & $1.7 \%$ & $100 \%$ \\
\hline 7 & Safe to operate than firewood & $13.3 \%$ & $75 \%$ & $6.7 \%$ & $3.3 \%$ & $1.7 \%$ & $100 \%$ \\
\hline 8 & Easy and fast to clean utensil & $15 \%$ & $80 \%$ & $3.3 \%$ & $1.7 \%$ & - & $100 \%$ \\
\hline 9 & Long life of utensil & $10 \%$ & $76.7 \%$ & $10 \%$ & $3.3 \%$ & & $100 \%$ \\
\hline 10 & $\begin{array}{l}\text { Production of organic food stuff through } \\
\text { slurry }\end{array}$ & $18.3 \%$ & $66.7 \%$ & $10 \%$ & $3.3 \%$ & $1.7 \%$ & $100 \%$ \\
\hline 11 & Sanitation in overall locality & $16.7 \%$ & $60 \%$ & $13.3 \%$ & $6.7 \%$ & $3.3 \%$ & $100 \%$ \\
\hline 12 & Increase mosquitoes/houseflies/insects & $100 \%$ & - & - & - & - & $100 \%$ \\
\hline 13 & Difficult to transport slurry to farmland & $100 \%$ & - & - & - & - & $100 \%$ \\
\hline
\end{tabular}

(Source: Field survey, 2020) ～(1=Strongly Agree, 2=Agree, 3=Neutral, 4=Disagree, 5=Strongly

Disagree)

Majority of respondents agreed that proper management of animal dung and human excreta through a biogas system creates a clean surrounding of home and society. Creation of a clean and healthy environment reduces the intensity of respiratory, water borne and air borne diseases. Majority of them agreed that biogas is easy and safe to use, the intensity of fire on people and houses is reduced after the use of biogas energy. Housewives/women are the main beneficiaries of the installation of biogas plants. Thus if concerned authority helps to manage the slurry for its transportation towards the field in the easiest way and introduce a covering system of slurry pit, all women become happy and satisfied with the biogas system.

\section{Economic relevance of biogas}

Table-3 reveals the response of the respondents on the question related to economic relevance of biogas. Majority of the respondents agreed that the number of livestock is 
increased to get dung and the rate of agricultural production per unit (kattha) is increased by using organic slurry. Majority have a common agreed voice about the saving of expenses on chemical fertilizers, medical services and costly fuel for cooking and lighting. There is no direct economic income of biogas so the majority of respondents disagree with the increased level of income and generation of employment for their family members. They justified that, they have no direct income and are saving economically but they just save from expected expenses on chemical fertilizers, medical services and fuel.

Table-3: Relevance of biogas in terms of economy

\begin{tabular}{|l|l|l|l|l|l|l|l|}
\hline SN & Variables & $(1)$ & $(2)$ & $(3)$ & $(4)$ & $(5)$ & Total \\
\hline 1 & Increase agricultural production & $15 \%$ & $66.7 \%$ & $8.3 \%$ & $6.7 \%$ & $3.3 \%$ & $100 \%$ \\
\hline 2 & Increase the number of livestock & $16.7 \%$ & $55 \%$ & $16.7 \%$ & $3.3 \%$ & $8.3 \%$ & $100 \%$ \\
\hline 3 & Saving of medicinal expenses & $8.3 \%$ & $70 \%$ & $6.7 \%$ & $8.3 \%$ & $6.7 \%$ & $100 \%$ \\
\hline 4 & Saving of fuel charge & $10 \%$ & $73.3 \%$ & $6.7 \%$ & $5 \%$ & $5 \%$ & $100 \%$ \\
\hline 5 & Saving the expenses of chemical fertilizers & $11.7 \%$ & $75 \%$ & $3.3 \%$ & $5 \%$ & $5 \%$ & $100 \%$ \\
\hline 6 & Increase the level of saving & $8.3 \%$ & $73.3 \%$ & $6.7 \%$ & $6.7 \%$ & $5 \%$ & $100 \%$ \\
\hline 7 & Increase the level of income & $6.7 \%$ & $25 \%$ & $50 \%$ & $15 \%$ & $3.3 \%$ & $100 \%$ \\
\hline 8 & Generate employment for family members. & - & - & $33.3 \%$ & $56.7 \%$ & $10 \%$ & $100 \%$ \\
\hline 9 & Enhance income generating skills & $10 \%$ & $45 \%$ & $23.3 \%$ & $10 \%$ & $11.7 \%$ & $100 \%$ \\
\hline
\end{tabular}

(Source: Field survey, 2020) (1=Strongly Agree, 2=Agree, 3=Neutral, 4=Disagree, 5=Strongly Disagree)

$45 \%$ respondents agreed that biogas related organizations play the catalytic role to provide various income generating skills with the collaboration of other organizations. Due to the response rate we can assume that it is essential to launch an effective package of income generating training over there. Biogas is women friendly. Biogas has played a role in changing the lives of women in rural areas. Use of biogas encourages women's participation in training for supervisor, masons and management of installation companies through women-friendly event management and also enhances income through sensitization on use of bio-slurry in vegetable farming, fish and pig raising. Get financial education and access to finance through co-operatives. Successes in the field have proved the effectiveness of gender mainstreaming in biogas programmed. 


\section{Social relevance of biogas}

Table- 4 reveals the response of the respondents about the relevance of biogas related to social aspects. Majority of respondents agreed that the biogas system reduced their work load and saved time. It has reduced the workload of women in household activities because they have spent less time on cooking, cleaning utensils and collecting firewood. Majority of them use their leisure time in social work, entertaining and informational programs on Radio and TV. Therefore, introduction of biogas technology has indirectly contributed to empower rural women as majority of them were regularly watching the TV, listening to the radio and reading the newspaper during the leisure time created by installation of biogas plants in the house.

Table-4: Relevanceof biogas in terms of social aspects.

\begin{tabular}{|l|l|l|l|l|l|l|l|}
\hline SN & Variables & $(1)$ & $(2)$ & $(3)$ & $(4)$ & $(5)$ & Total \\
\hline 1 & Increase leisure time & $21.7 \%$ & $66.7 \%$ & $8.3 \%$ & $3.3 \%$ & & $100 \%$ \\
\hline 2 & Increase Social interaction & $23.3 \%$ & $65 \%$ & $6.7 \%$ & $3.3 \%$ & $1.7 \%$ & $100 \%$ \\
\hline 3 & Effective management of family & $31.7 \%$ & $58.3 \%$ & $8.3 \%$ & $1.7 \%$ & - & $100 \%$ \\
\hline 4 & Involve in family interaction & $33.3 \%$ & $50 \%$ & $10 \%$ & $6.7 \%$ & - & $100 \%$ \\
\hline 5 & Involve in social work & $16.7 \%$ & $53.3 \%$ & $16.7 \%$ & $8.3 \%$ & $5 \%$ & $100 \%$ \\
\hline 6 & Complete home work on timeby children & $25 \%$ & $56.7 \%$ & $10 \%$ & $5 \%$ & $3.3 \%$ & $100 \%$ \\
\hline 7 & Getting more information & $25 \%$ & $50 \%$ & $16.7 \%$ & $5 \%$ & $3.3 \%$ & $100 \%$ \\
\hline 8 & Involve on entertaining program & $20 \%$ & $56.7 \%$ & $10 \%$ & $8.3 \%$ & $5 \%$ & $100 \%$ \\
\hline
\end{tabular}

(Source: Field survey, 2020) (1=Strongly Agree, 2=Agree, 3=Neutral, 4=Disagree, 5=Strongly Disagree)

Majority of women realized that after the installation of a biogas system, frequency of social interaction increased. Women have sufficient time for socialization and participation in social activities, meetings. From participating in various activities they get confident and strongly express their feelings to others .Women's group also organizes different kinds of programs to enhance and develop new skills like tailoring, farming and woolen sewing and also get opportunity to socialize. A majority woman responds that high frequency of family interaction helps to understand the problems of family and manage them on time. They have enough time to motivate their children about homework. They can spend more time with family members nowadays. 


\section{Conclusion}

There is no direct and immediate economic return of biogas plants. It creates indirect benefit to all family members. Due to the immediate and close touch of women with biogas related activities, it provides more benefit towards women than other family members. By reducing the rush schedule of domestic burden, it creates favorable time for socialization through watching TV, listening to radio and interaction with villagers. By reducing the smoky environment in the kitchen, it maintains sanitation and reduces the intensity of diseases. By producing fertile slurry, it increases production and productivity of farmland and fulfills the nutritional requirement of all family members. By reducing expenditure on costly fuel such as LPG, kerosene, coal and firewood etc for cooking and lighting, it helps to boost up saving economically and forest area environmentally.

Status of health and sanitation of women were positively changed through the use of biogas .It helps to increase the life expectancy of people by reducing the risk of various communicable and non communicable diseases. Since the use of biogas in the house, the living standard of women is uplifted. Healthy and happy women can create a heavenly environment in the family. People can change their traditional attitude through perceived benefits from biogas. Nowadays, people connect toilets to the biogas system. It is essential to motivate farmers to use the biogas system by educating them about its direct and indirect benefit. The visible positive impacts on the health and livelihood of rural families utilizing biogas have led their neighbors to adopt biogas systems as well.

Women biogas users' groups must be formed and launch women empowerment programs by focusing on their leisure time to provide training of income generating skills, packaging and marketing of organic compost fertilizer through slurry and organic farm products through organic farming system. Provision of soft loans by financial institutions should be managed with group collateral. It creates direct benefits to women through their group solidarity politically, socially and economically. Concerned authority must understand the end-user needs and concerns and design a product that meets the needs and addresses the concerns. So it is essential to assess the needs and conditions of the end-user and to determine the suitability of the available biogas technologies to fit them. In Nepalese context women are the actual end users of the biogas system.

\section{References}

Alternative Energy Promotion Centre.(2005).Biogas technology. [Blog post] Retrieved from https://www.aepc.gov.np/biogas-technology

Giordano, P., Pelizan, L. \&Alavi, A. R. (2018 Sep) Nepal Biogas Support Program (BSP): Cooking With Clean and Affordable Energy in Rural Areas. Retrieved from https://media.iese.edu/research/pdfs/OP-0301-E.pdf

Lewis, J.J. (2019 may 30).cultural feminism. Retrieved from https:// www.thoughtco.com/culturalfeminism-definition-3528996

Regan, C. (2012 Oct 2) .women and development.Development education. Retrieved fromhttps://developmenteducation.ie/feature/women-development/

World Bank. (2011).world development report 2012: gender and development. Washington DC.USA 